\title{
Relocation: To be or not to be a black diamond in a South African township?
}

\author{
Ronnie Donaldson ${ }^{\mathrm{a}, *}$, Thobeka Mehlomakhulu $^{\mathrm{b}}$, Dan Darkey ${ }^{\mathrm{c}}$, Michael Dyssel ${ }^{\mathrm{d}}$, \\ Pakama Siyongwana ${ }^{\mathrm{e}}$
}

${ }^{a}$ Department of Geography and Environmental Studies, University of Stellenbosch, 34 Van der stel Street, Stellenbosch, South Africa

${ }^{\mathrm{b}}$ Department of Geography, University of the Free State, Bloemfontein, South Africa

${ }^{c}$ Department of Geography, Geoinformatics and Meteorology, University of Pretoria, Pretoria, South Africa

${ }^{\mathrm{d}}$ Department of Geography, University of the Western Cape, Cape Town, South Africa

${ }^{\mathrm{e}}$ Department of Geography, Nelson Mandela Metropolitan University, Port Elizabeth, South Africa

Keywords:

Black diamonds

Township

Relocation

Post-apartheid

Black middle class

\section{A B S T R A C T}

\begin{abstract}
Beginning in the mid-1990s, South Africa's geopolitical, social and economic landscapes have been rapidly transforming. Driven primarily by government policy particularly after 1994, these changes have among other effects offered tailor-made opportunities to the educated and resourceful black South Africans (so-called 'black diamonds') in the townships to rise on the socio-economic ladder. The main question this research paper attempts to answer is why only some of black middle-class township dwellers (black diamonds or BDs) do not relocate to former whites-only suburbs? The study, conducted on BDs in the townships of Bloemfontein, Cape Town, Port Elizabeth and Pretoria, reveals the role of cultural, social, spatial, political and economic factors in the residential-location decisions of the black middle class. The survey found a duality of social identities emerging within the black middle class which could no longer be perceived as a single cohort. These identities may be categorized as the BDs who live in, educate their children there and are assimilated into the historically white suburb culture and those who are inextricably enmeshed in the townships. This paper also reports that there are other incentives, incorporating unquantifiable socio-economic benefits, that keep BDs 'sparkling' in the townships because they may be absent in the former whites-only suburbs. Although their consumption power may be of most interest to economic planners and analysts, their role in the townships transcends economics into some being seen as role models.
\end{abstract}

\section{Introduction}

Residential desegregation has taken place at various levels across South Africa since the scrapping of the Group Areas Act in 1991. Some members of the black middle class are tempted to move to the former white suburbs - as a symbol of increased social status - whereas others are satisfied to stay in the townships. The term middle class has intricate political and social underpinnings. This study does not deal in detail with definitional issues, instead the black middle class is defined according to their relatively higher income (earning more than the gap-housing category total of R12,000 per month) that allows them to own certain goods and afford special services. This class is also defined as a group characteristically engaging in white-collar professional jobs thanks to their acquisition of higher levels of education and skills (Simpson,

\footnotetext{
* Corresponding author.

E-mail address: rdonaldson@sun.ac.za (R. Donaldson).
}

2008). With the exception of one study (Siyongwana, 2011) that shows the contrary, racial movement has primarily been in one direction with blacks relocating from townships to suburbs (Donaldson \& Kotze, 2006; Seekings, 2000). The black middle class is moving to the metropolitan suburbs to be closer to work, for better security and to be closer to good schools for their children (Van Eyk, 2008). An accurate count of the black middle class awaits the results of the 2011 census although there are a number of estimates, ranging from 2.6 million (UCT Unilever Institute of Strategic Marketing, 2007) to 9.5 million (Udjo, 2008). They are geographically, living mainly in the major metropolitan areas with "66\% of black diamonds living and working in Gauteng (mostly in Johannesburg), followed by KZN with the second highest concentration, the Eastern Cape, the Western Cape and finally the Free State. Within these provinces, there has been a noticeable shift of BDs from living in the townships to living in the suburbs. In 2005 , $77 \%$ of BDs still lived in townships compared to more recent figures for 2007 which indicate that this has dropped to 53\%" (Foxcroft, 
2009: 32). According to The African Response (2009), the emerging black consumer is often defined under monolithic terms such as 'buppies' (black upcoming professionals). The term black diamond (coined in the TNS and UCT Unilever Institute survey in 2007) is an emerging, yet highly contested and growing concept. In gemmological terms black diamonds are considered to be great treasures as they are the rarest of all diamonds. Congruently, a sociological understanding of BDs should ideally reflect some kind of desirable status symbol. We use three segments to differentiate between the emerging BDs. First, it encompasses a category of blacks who are well-off through hard work but who are not necessarily highly educated. Second, blacks who are prosperous because they are better educated and therefore have managed to get well-paid jobs. Third is a dubious group of blacks who are wealthy because they are politically aligned to the ruling party, having greater access than others to government-related projects and employment opportunities. Perhaps, the connotations which the latter category carries partly account for the negative perceptions of many regarding the black-diamond terminology.

The main questions this paper addresses are: Why, given the ideal opportunity to do so, black diamonds (BDs) who can afford to live in more affluent areas (i.e. former white suburbs) are not relocating? What factors are keeping them in the townships? If they do stay in the townships, what social ties and networks do they have with black diamonds now living in former white suburbs and how are they culturally and economically tied to these former white areas? And, to what extent are their children assimilated into former white areas, for example, the schools they attend.

Answers to these questions will provide a better understanding of the complexities of a BD identity and this may give greater clarity of a polarized BD community (one group living in suburbs, another in townships) seemingly emerging in urban South Africa. The methods used in the study were two-fold. First, a review of existing literature (of which there is a dearth) with consumer reports comprising the majority of published research on the emergence of BDs. This review provided the context for the analysis. Second, face-to-face interviews were conducted with the BDs who after 1994, despite the scrapping of racial laws, opted not to relocate to the former whites-only suburbs. Townships, also called 'locations' or 'lokasie' or 'Kasie', are still usually referred by these names in most townships. The 'eKasie' has evolved as a unique community with a vibrant culture. A new element in the mix is a rapidly-growing middle class with enormous spending power who prefer to stay in the townships rather than in the suburbs. In total, $180 \mathrm{BDs}$ were interviewed in the townships of a major urban area in four of the country's provinces (Cape Town, Bloemfontein, Port Elizabeth and Pretoria). In total 45, interviews were conducted per city. BDs were identified in the following townships: Gugulethu, Khayelitsha and Du Noon in Cape Town, Mamelodi in Pretoria, New Brighton, Motherwell, KwaZakhele, KwaMaGxaki-KwaDwesi in Port Elizabeth, and Bloemanda, Grasslands, Bloemside and Unique Homes in Bloemfontein. A purposive sample used observable indicators such as possession of trendy cars, sizable modern houses and digital television dishes as the initial selection criteria. Other BDs were tracked by means of a snowballsampling technique. The face-to-face interviews were conducted over a period of 6 weeks. The survey questionnaire covered household demographics; length of stay in the township; attitudes towards the BD label; preference for a township lifestyle despite advancement up the socio-economic ladder; links with family and friends in the suburbs; other reasons for remaining in the townships; and attitudes of family members to their remaining in the townships.

\section{Black diamonds in context}

Research on South Africa's black middle class in general and BDs in particular has received little attention (Southall, 2004a, 2004b, no date; The African Response, 2009). Various criteria have been used to define the middle class. Nhlapo \& Anderson (2010) identified a set of aspects of material standard of living to define a middle-class standard of living for South African households. The criteria are whether households reside in formal housing, have a domestic water tap, a flush toilet, electricity as the main lighting source, electricity or gas as the main cooking source, and have a landline telephone or a household member has a cellphone. Nhlapo \& Anderson's study, based on official Statistics SA census data, showed that between 1998 and 2006 the per cent of all South African households with a middle-class standard of living changed little from 1998 to 2006, increasing from 23\% to only 26\%. By 2006 whites (85\%) and Asians (75\%) were still mostly in the middle-class group whereas coloured (48\%) and black households (22\%) were only marginally middle class. According to Weberian and Marxist definitions of middle class, the concept refers to occupational groups of managers and professionals (Erickson \& Goldthorpe, 1993; Southall, 2004a). Intellectual and political events are said to distract attention in research agendas on the black middle class in favour of an emphasis on the marginalized black urban poor.

Africa is experiencing a rapid rate of economic growth, estimated to be $7 \%$ in 2011 , primarily driven by a growing prosperous consumer market created by new demands by black middle-class citizens living in cities (Kaberuka, 2010). In many African countries the present increase in private consumption and spending power exhibits a complex interplay between poverty alleviation and keeping up with the Joneses. This interplay is highly visible in South Africa where much attention is beginning to be paid to the rise of the new black middle class and their propensity to purchase (Ibsen, 2010). Indeed, much of the research and interest in black diamonds has an economic focus. Some scholars see them as the engine of the South African economy (Brulliard, 2010; Commins, 2007; Goyal, 2010; Van Eyk, 2008). Others question the clout the black middle class has to play and significant role as an economic driver (Macozoma, 2006; Newsweek, 2009; Sikhakhane, 2009a, 2009b). Consumer studies attest that being a member of the black middle class ensures that their children enjoy the same or even better lifestyle than themselves (Simpson, 2008). The lifestyle of the black middle class is evidenced by their buying behaviour and it manifests in products such as homes, cars, clothing, cellphones, TV sets, electronic equipment and electrical appliances. However, Mokotso (2009) argues that the extensive contribution of BDs to the economy is unsustainable because spending has not been aimed at attaining wealth-creating assets. Instead, spending on luxury items is financed by a growing level of personal debt. Similarly, Schlemmer (2005: 126) points out that the black middle class is "not yet consolidated and secure in terms of assets, status, and self-image" and that this group is of very recent origin...clearly the product of very rapid and recent occupational mobility" (Schlemmer 2005: 133), which explains their "feelings of economic vulnerability" (Schlemmer 2005: 137).

The African Response (2009) indicates that only recently have marketers begun to acquire some knowledge of the black middle class, knowledge that is anecdotal rather than statistical or quantitative. The emerging black consumer or black upcoming professional drives smart cars, wears branded clothes and has huge debts. Most of urban BDs (53\%) are living in townships and 32\% in former white suburbs (Mail and Guardian, 2009). It appears that although the segregation boundaries have been removed, most of the black middle class prefer to stay in the townships.

According to Randall (1996: 661) official development thinking by the 1990s asserts that "the expansion of the state's role from the preferred minimalist function of providing the legal and macroeconomic regulatory framework for capital accumulation, to a more profound intervention in the productive process. As a remedy, the 
state would have to be restrained from usurping the primary role which the market's invisible hand ought to be playing." In 2005, whites owned almost two thirds of the companies listed on the Johannesburg Stock Exchange, 30\% were owned by foreigners, and only 4\% was controlled by blacks. By 2010 black ownership accounted for $36 \%$, while direct ownership of the top 100 companies amounted to $8 \%$ (Bauer, 2010). The end of racial discrimination and the introduction of policies of affirmative action have facilitated the effective incorporation of a black wealthy class into the middle class (Lester, Nel, \& Binns, 2000). Southall (2004b: 17) contends that

"the most obvious point is that a fairly rapidly growing black (new) middle class is the prime beneficiary of ANC rule. The liberation struggle against apartheid objective had as its prime objective the capture of state power... This transformation is the single most important factor accounting for the present rate of growth of the black middle class, and is clearly instrumental in consolidating if not accelerating the growth in the distribution of national income accruing to blacks. Even so, various fractions of the black middle class have shared these benefits differentially."

The emergence of BDs and their sustainability are attributable to the government's commitment to the transformation of every aspect of society. The most powerful factor has been increased access to a wide range of jobs. The employment-equity legislation and the industry charter ensure black economic empowerment and radical transformation of the civil service by putting tremendous pressure on employers to implement these policies (Simpson, 2008). This has a major impact on the sustained growth of the black middle class. The Broad-Based Black Economic Empowerment (BBBEE) Act defines the BBBEE as the economic empowerment of all black people through socio-economic strategies (Esser \& Dekker, 2008). Two propositions regarding BEE as growth catalyst are made by Andrews (2008: 39 \& 47):

"Proposition 1: BEE will catalyze growth if it facilitates the changes....It will be particularly successful if, in opening the economy to PDI's [previously disadvantaged individuals], it also opens the economy to new ideas, entrepreneurs, and laborabsorbing, export-enhancing activities" and "Proposition 2: BEE will not catalyze growth because it will not lead to effective structural change in the South African economy. Institutional macrostructures that underlie the economic patterns limiting racial transformation and growth are rigid and do not change easily; they are especially protected by elites with an interest to maintain them."

The emergence of just "a few black beneficiaries, and the question of how broad black economic empowerment should be (in numbers of beneficiaries as well as elements)" (Andrews, 2008: 33) are concerns raised by some who view the government's BEE policy as creating rich but tiny enclaves of elites in South Africa. Another concern is that black empowerment is politically driven and the beneficiaries are the people with connections in the ANC leadership. Sikhakhane (2009b: 25) warns that these policies are the umbilical cord connecting the black middle classes to the

“government and its largesse....So long as the government does not reduce the flow of economic nutrients to the middle class, it will remain on the sidelines of our politics, paying no attention to the rape of democracy and its institutions by the ruling party. The middle class in Zimbabwe behaved in similar fashion. It stood by and kept quite when the first signals of Robert Mugabe's dictatorial tendencies showed up."

It is useful to emphasise the importance of the township property-market dynamics as a context for the partial spatialrelocation inertia exercised by BDs regarding maintaining a foothold and presence in townships. House prices in black townships are raising steadily compared to those of suburban houses. The property barometer of First National Bank (2011) identified a number of tendencies driving this apparent superior performance of the township-housing markets. One of these is that the pace of black migration to the suburbs has slowed, perhaps due to affordability issues in some instances. A hint of this "slowdown is seen in the FNB Estate Agent Survey, where agents surveyed in the first three quarters of 2011 have estimated black-population-group buyers at a mildly lower $27.3 \%$ of total buyers, compared to $31.3 \%$ of total suburban buyers in 2010" (First National Bank, 2011). The suburbs of the 1970s that transformed from mono-functional residential dormitories to suburbs with malls and businesses on their doorsteps are analogues of townships today transforming from dormitory areas to mixed-use areas. Townships have become "attractive places to live and....property there is cheaper" (Steward, 2009: 6).

\section{Case-study findings}

In the following sections the findings are presented under four headings. First, a demographic profile of BDs is outlined; then their property-ownership details are reported; followed by an account of their attitudes towards being labelled BDs; and last their broader links with the suburbs and their relocation preferences are examined.

\section{Demographic profile}

Schlemmer (2005: 133 as cited by Nieftagodien \& van der Berg, 2007: 5) has observed that the "black middle class is being augmented by 'rapid accruals' of new entrants all the time, so that it may take some time for them to develop an own identity. [But] the black middle class is likely to have two distinct sub-groupings for some time to come, those who have recently joined and those who are longer established in the middle class; consumer patterns are likely to reflect this." The UCT Unilever black-diamond survey reported that there is no homogenous black middle-class or BD group. That study identified four middle-class categories (Table 1)

Table 1

Middle class groups.

\begin{tabular}{|c|c|c|c|}
\hline The established & Young families & The start-me-ups & The Mzanzi youth \\
\hline $\begin{array}{l}\text { - Aged 35-49 } \\
\text { - Intellectuals } \\
\text { - Reasonably well established } \\
\text { - Most married with } \\
\text { school-going children } \\
\text { - Most live in suburbs } \\
\text { - Strong drivers of the economy } \\
\text { - Very politically aware: many were } \\
\text { in exile during apartheid }\end{array}$ & $\begin{array}{l}\text { - In their 20s and 30s } \\
\text { - Half are single } \\
\text { - Three quarters have children under six } \\
\text { - Live in suburbs and townships } \\
\text { - Highly aspirational - the 'buppies' of this class } \\
\text { - Not as highly educated as the established } \\
\text { - Less concerned with politics }\end{array}$ & $\begin{array}{l}\text { - Aged 18-29 } \\
\text { - Largely male } \\
\text { - Mostly single and childless } \\
\text { - Majority live with their parents } \\
\text { - Highly disposable income } \\
\text { - White-collar jobs } \\
\text { - Highly positive - "on their way up" } \\
\text { - Less interested in politics }\end{array}$ & $\begin{array}{l}\text { - Aged } 18-24 \\
\text { - Mostly single and childless } \\
\text { - Students } \\
\text { - Low income } \\
\text { - Highly optimistic } \\
\text { - View education as key to better future } \\
\text { - Happy to live in township } \\
\text { - Not too interested in politics }\end{array}$ \\
\hline
\end{tabular}


which this research to some extent confirms in terms of composition. The case studies revealed that the age categories of respondents reflect a good mix of early starters (18\%), those in the early-mature stage of the life-cycle (36\%), those of mature age (41\%), and those in retirement (5\%). The majority $(60 \%)$ are married and have an average of three children, some $82 \%$ have a post-school qualification and nearly three out four (72\%) households earn between R25,000 and R35,000 per month. Sixty per cent are employed in professional, technical or managerial positions and $26 \%$ work in services or salesrelated activities. Others are self-employed. Significantly, one third is employed in a township. Employment mobility is a key characteristic of BDs in the post-apartheid era. The government's policy on affirmative action as well as the radical transformation of the public service has contributed to the relatively rapid absorption of black employees into the economy. Unexpectedly, the survey revealed that $43 \%$ of the respondents had held the same job since $1994,26 \%$ had had two different jobs and only $31 \%$ had been in three or more positions.

\section{Property ownership}

A mere $8 \%$ of the respondents rented the house they were living in when interviewed. Six per cent own another property in the township in which they reside. Almost a quarter (23\%) own other properties, $24 \%$ of which are in suburbs, $35 \%$ in other townships and $24 \%$ in a rural village. It is noteworthy that $54 \%$ of those owning second homes use them whereas $22 \%$ offer them as rental accommodation.

\section{Attitudes towards labelling}

Racial labelling is detested by most South Africans owing to the country's political history. Fittingly, the epithet 'black diamond' was resented two thirds of the respondents. Their aversion is encapsulated in statements such as:

"Why should African people be classified? Do we ever speak of white diamonds? The term has connotations of conspicuous consumerism and materialism."

"The concept is denigrating and derogatory to black people."

"I dislike classification."

A question linking successful black individuals with BDs yielded the responses shown in Table 2. It appears that social standing in the community is best reflected in being seen as role models for township children. Success in general (57\% agreement) is associated with the term BD and much less so with where one resides. The general portrayal of BDs in the media and by opposition political parties as a select group of black elite benefiting financially from the black empowerment post-apartheid legislative policies, is not strongly supported by the findings as more than half (53\%) disagree with the contention that BDs are beneficiaries

\section{Table 2}

Opinions on being referred to as successful black individuals.

\begin{tabular}{lllc}
\hline Statements regarding successful black individuals & Agree & Neutral & Disagree \\
\hline $\begin{array}{l}\text { You are considered as a role model } \\
\quad \text { for township children }\end{array}$ & $65 \%$ & $27 \%$ & $8 \%$ \\
$\quad$ You are a successful black person & $57 \%$ & $32 \%$ & $11 \%$ \\
$\quad$ You are black elite living in a township & $37 \%$ & $35 \%$ & $28 \%$ \\
$\quad \begin{array}{l}\text { You are a beneficiary of black economic } \\
\quad \text { empowerment }\end{array}$ & $21 \%$ & $26 \%$ & $53 \%$ \\
$\quad \begin{array}{l}\text { You are a person ready to relocate } \\
\quad \text { from the township to a suburb }\end{array}$ & $20 \%$ & $33 \%$ & $47 \%$ \\
$\quad$ You are a black elite living in a suburb & $20 \%$ & $31 \%$ & $49 \%$ \\
\hline
\end{tabular}

of BEE. Most of the $21 \%$ who agree live in Pretoria, Bloemfontein and Cape Town and the least in Port Elizabeth. It is not coincidental that the former three cities are the institutional hubs of their provinces, whereas Port Elizabeth does not serve as a seat of provincial government.

\section{External socio-economic linkages}

The BD township-residents' geographies of intra-and intertownship spatial mobilities on the one hand and suburb-township cultural mobilities and reciprocities on the other hand, provide insight into the emerging social dynamics of BDs. An overwhelming majority of respondents indicated that family or close friends have moved to the suburbs since 1994 and it appears that these relational ties are being upheld by the BDs' frequent visits to the suburbs. Because BDs strongly believe in their established cultures and traditions, these impact heavily on their lives and decisionmaking. A slight majority (52\%) indicated that cultural life in suburbs is too Eurocentric (for whites only). In the popular media, living the suburban lifestyle is typically represented as residents living behind high walls where security is a prime consideration. Khan (2004, p. 1) has called attention to the discourse on fear and how this is shaping urban form to reinforce patterns of segregation, fragmentation and social exclusion. Interestingly, when asked to voice their opinion whether security in the township is better than in the suburbs, most (39\%) disagreed. The suburbs appear to be better options regarding security, notwithstanding the perceived rise in crime rates and flourishing of gated communities in these areas.

It is this socially-constructed sense of being an outcast that township BDs resent most of suburban life and the reason why most (77\%) indicated that they enjoy the social life in townships more than they would that of a suburb. Also, this spirit of ubuntu (an African philosophy of life meaning a person is a person because of one's relationship with others) engenders reluctance to relocate because ubuntu is perceived to be non-existent in the suburbs. The essence of $u$ buntu is wanting to be part of the community and living a shared destiny for the benefit of all. Most (60\%) township BDs are regularly visited by their family or friends living in the suburbs, with only $29 \%$ receiving occasional visits.

When BDs were asked if they would consider relocating to the suburbs; $46 \%$ of all the respondents answered that they might in the near future. Cape Town's BDs are the most likely (59\%) to move to a suburb with Port Elizabeth (44\%), Pretoria (41\%) and Bloemfontein's (40\%) the least likely. Concerning the length of stay in a township, the majority (60\%) of those who have been living in the townships since 1994 or later expressed their wishes to relocate. Respondents who have been lived in the same township since before 1994 have the least desire to relocate because their social ties and the community structures that have developed over decades are more important to them than a new and unknown residential environment.

The black middle class continues to grow and to occupy an important position on South Africa's socio-economic scene. Ibsen (2010) contends that the lives and mindset of black middle-class consumers, their consumption preferences and their choices are attributable to their culture and South Africa's racial past so that they tend to do things previously forbidden by apartheid legislation. It is not surprising that most respondents prefer not to shop in the townships but in the trendy suburban malls (43\%) and to lesser extent the metropolitan central business areas (26\%).

The BDs were also asked to indicate where their friends reside and the answer demonstrated that the social geography of networking and friendships is much racialised with $84 \%$ socialising with fellow blacks (of whom $67 \%$ live in townships and $17 \%$ in the 
suburbs) compared to only $16 \%$ belonging to other population groups. Social networks remain insulated in the townships.

A core aim of the research is to understand why BDs choose to stay in the townships. When asked what they like most about living in a township, the following were mentioned: ubuntu (57\%), voluntary segregation based on race, lifestyle and language (50\%), affordability and location (29\%), and cultural events $18 \%$ (do not add to $100 \%$ due to multiple responses). The foremost dislike of living in a township relates to crime and the lack of safety (87\%). Other dislikes are noise and polluted environments (24\%); poor services (21\%); poverty (9\%); overcrowding (6\%); social relationships (6\%); and poor accessibility to work and shopping facilities (3\%). Clearly, the philosophy of ubuntu is dear to respondents. This, coupled with the vibrant township culture for which they are willing to voluntarily segregate themselves, constitutes the main drawcard of the townships. Ironically, crime (which is in direct opposition to ubuntu) is the greatest push factor driving the black middle class from the townships. Thus, efforts aimed at keeping the middle class in the townships should primarily deal with crime reduction.

\section{Conclusion}

Black diamonds opt to stay in the townships and disassociate themselves from being stigmatized as such, remain hidden treasures in the social make-up of cities. Some protest that the term implies superiority and attempts to set them apart from their communities. This study verifies that the townships remain the preferred choice of residence for many of the emerging black South African middle class. Social, cultural and, to a lesser degree, economic reasons account for this choice. The township traditions and social networks constitute strong bonds which keep the BDs shining in the townships rather than becoming invisible beings in the suburbs. Although some BDs tend to flaunt their possessions in an in-your-face manner this is not wholly uncharacteristic of township style. Gold chains, labelled shirts, designer shoes and fancy cars are traditionally acceptable, indeed admired, in townships without detracting from the ubuntu spirit. Most of the BDs see themselves as role models in the townships. South Africa's socio-economic history necessitates the grooming of a vibrant black middle class but more important is to develop a productive and savings culture as part of the nurturing process if the black diamonds are to become a relevant and sustainable economic factor. Refining this in the townships will have more positive ripple effects than relocating these attitudes to the suburbs. Accordingly, issues that push BDs out of the townships need to be investigated.

\section{References}

Andrews, M. (2008). Is black economic empowerment a South African growth catalyst? (Or Could It Be...). Harvard Kennedy School. Faculty Research Working Papers Series. RWP08-033. , pp. 106.

Bauer, N. (2010). Black ownership on the JSE 100 accounts for 18 \%. Business Day, Published 2010/09/01.

Brulliard, N. (2010). South Africa's "black diamonds" overtake whites. GlobalPost, May 19.

Commins, L. (2007). Black diamonds drive economy. June 13, 2007. The Mercury, 3.

Donaldson, R., \& Kotze, N. (2006). Residential desegregation dynamics in the South African city of Polokwane. Journal of Social and Economic Geography, 97(5), 567-582.
Erickson, R., \& Goldthorpe, J. (1993). The constant flux: A study of class mobility in industrial societies. Oxford: Clarendon Press.

Esser, I., \& Dekker, A. (2008). The dynamics of corporate governance in South Africa: broad based black economic empowerment and the enhancement of good corporate governance principles. Journal of International Commercial Law and Technology, 3(3), 157-169.

First National Bank. (2011). Property barometer - Former township house prices. Former Black township house price growth still outperforms the rest 27 October 2011.

Foxcroft, M. (2009). Growing the consumption of wine amongst emerging market consumers in South Africa. Assignment submitted in partial fulfilment for the Cape Wines Master Diploma. January, 2009.

Goyal, M. (2010). South Africa: rise of the black middle class. Forbes India Magazine, 18 June 2010.

Ibsen, H. (2010). Black diamonds in South Africa. A history of consumption culture among the new black middle class, 1994-2010, Unpublished. Hilde Ibsen, Department of Health and Environmental Science, Karlstad University, Sweden.

Kaberuka, D. (2010). Africa's economic growth. Speech by Donald Kaberuka, President of the African Development Bank, addressed to the AfDB Committee of Ten (C10) in Cape Town, 21 February 2010.

Khan, F. (2004). Uneven development, ambiguous restructuring and enduring polarization, development update the city and its future: The eternal question, Vol. 5.

Lester, A., Nel, E., \& Binns, T. (2000). South Africa's current transition in temporal and spatial context. Antipode, 32(2), 135-151.

Macozoma, S. (2006). Black middle class 'only a myth'. Speech delivered at Wits Business School, 07 November 2006.

Mail and Guardian. (2009). Townships still home to many, but emigration beckons. Accessed 09.10.09.

Mokotso, M, (2009). The creation and sustainability of the black middle class in the Western Cape. Unpublished Master of Technology: Public Management. Cape Peninsula University of Technology. http://dk.cput.ac.za/td_cput/356 Accessed 18.09.11.

Newsweek. (2009). South Africa hits a wall. Why middle-class growth is ending. Newsweek, 30 October 2009.

Nieftagodien, S., \& van der Berg, S. (2007). Consumption patterns and the black middle class: The role of assets. Stellenbosch Economic Working Papers: 02/07. A working paper of the Department of Economics and the Bureau for Economic Research at Stellenbosch University.

Nhlapo, M. S., \& Anderson, B. A. (2010). Profiling South African middle class households: 1998-2006. Pretoria: Statistics SA. www.statssa.gov.za/publications/ Report-03./Report-03-03-01.pdf Accessed 05.12.11.

Randall, D. J. (1996). Prospects for the development of a black business class in South Africa. The Journal of Modem African Studies, 34(4), 661-686.

Schlemmer, L. (2005). South Africa's new middle class. Chapter 5. In A. Bernstein, \& S. Johnston (Eds.), The next decade: Perspectives on South Africa's growth and development (pp. 112-140). Johannesburg: Centre for Development and Enterprise.

Seekings, J. (2000). Introduction: urban studies in South Africa after apartheid. International Journal of Urban and Regional Research, 24(4), 832-840.

Sikhakhane, J. (2009a). South Africa: recession has exposed frailties of black middle class. Business Day, 21 September 2009.

Sikhakhane, J. (2009b). The black middle class might follow Zim and turn a blind eye. Cape Argus25, 26 July.

Siyongwana, P. (2011). Post-colonial African urbanization: growth and racial integration challenges in South African small towns; ('dorps') since 1994: Some indicators to Port St Johns (Umzimvubu). Unpublished paper, NMMU, Department of Geography.

Simpson, J. B. (2008). Black diamonds: the new South African middle class. Management Today, 24(4), 43-46.

Southall, R. (2004a). Political change and the black middle class in democratic South Africa. Canadian Journal of African Studies, 38(3), 521-542.

Southall, R. (2004b). South Africa's emerging black middle class. South African Labour Bulletin, 28(4), 26-27.

Southall, R. (no date). Political change and the black middle class in democratic South Africa. http://ccs.ukzn.ac.za/files/Black\%20Middle\%20Class\%20in\%20SA3. pdf Accessed 20.15.11.

Steward, T. (2009). Bucking the trend. Business Times, 1 February 2009. http://www. netassets.co.za/article.aspx?id=930680 Accessed 12.11 .11 .

The African Response. (2009). www.africanresponse.co.za Accessed 10.09.10.

UCT Unilever Institute. (2007). www.unileverinstitute.co.za Accessed 20.11.10.

Udjo, E. O. (2008). The demographics of the emerging black middle class in South Africa. Bureau of Market Research, UNISA, Research Report no 375.

Van Eyk, R. (2008). South Africa: A black diamond booster. Business Day, 14 November. 